\title{
UNIVERSIDADES ACESSÍVEIS DO RIO DE JANEIRO: EU NÃO CONSIGO VER
}

\section{ACESSIBLE UNIVERSITIES IN RIO DE JANEIRO: I CANNOT SEE}

\author{
Íris Carlota dos Santos Arraes ${ }^{1}$, Mestranda em Design \\ Cláudia Mont’Alvão ${ }^{2}$, D.Sc., Professora Associada \\ (1) PPG Design PUC-Rio e-mail: iriscarlotavib@gmail.com
}

(2) PPG Design PUC-Rio e-mail: cmontalvao@puc-rio.br

Palavras-chave: Deficiência visual, Ergonomia, Acessibilidade

\begin{abstract}
A acessibilidade ao ensino superior no Estado do Rio de Janeiro apresenta verdadeiros abismos de compreensão quando colocada no contexto da pessoa com deficiência visual. Este artigo apresentará as principais etapas vivenciadas por estes candidatos; as barreiras reveladas neste processo e a contribuição das abordagens do design para o tema.
\end{abstract}

Key-words: Visual Impairment; Human factors, Accessibility

The accessibility steps to reach the higher education in Rio de Janeiro presents a significant misunderstanding when faced by people with visual impairment. The present paper will introduce the mainly steps; the barriers faced by them in these process of transition, and what the design approaches can offer to this subject.

\section{Introdução}

A acessibilidade e a interação entre o ser humano e os sistemas são elementos indispensáveis na prática de projetos em Design. Os estudos e investigações fundamentados nos preceitos da Ergonomia, assim como a vivência do Design em suas diferentes abordagens, vem ao longo dos anos se sedimentando como forte aliado para a viabilização de sistemas acessíveis.
Mesmo com tantos tratados e leis, o Brasil ainda se encontra em vias de tornar realidade a acessibilidade ao ensino superior, principalmente quando se fala de acessibilidade para os candidatos com deficiência visual.

A jornada em busca dos cursos de graduação, que tem início nas inscrições para os processos seletivos, é feita através de sistemas informatizados que nem sempre lhes asseguram o
Realização:
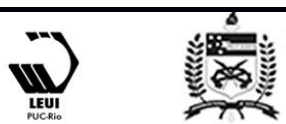


\section{$16^{\circ}$ \\ ERGODESIGN USIHC CINAHPA}

acesso à informação necessário. Vencida a etapa das inscrições por meios digitais, o candidato com deficiência visual se depara com outras barreiras de acessibilidade na realização das provas; $\mathrm{e}$ vencida mais esta etapa; chega o momento do encontro com as barreiras de acessibilidade concernentes ao seu aprendizado em sala de aula.

O presente artigo tem por objetivo apresentar algumas das barreiras de acessibilidade presentes nas etapas desta transição, como elas são classificadas e quais abordagens do Design e métodos da Ergonomia existentes podem contribuir para viabilizar a acessibilidade necessária.

Os dados preliminares apresentados neste artigo, foram obtidos através de análises documentais, levantamentos bibliográficos e pesquisa de campo, que fazem parte do processo pesquisa que se encontra em andamento, realizada para uma dissertação mestrado.

\subsection{As pessoas com deficiência visual em busca do ensino superior no Rio de Janeiro}

De acordo com a última revisão da Classificação Internacional de Doenças em 2006, existem 4 diferentes níveis de acuidade visual [WHO, 2014]. São elas: visão normal; deficiência visual moderada, deficiência visual severa e cegueira.

Agrupam - se sob o termo "baixa visão" os indivíduos do grupo de pessoas com deficiência visual moderada, somadas ao grupo de pessoas com deficiência visual severa, e aponta-se como principal causa para essas deficiências, erros de refração não tratados corretamente.

O grupo de portadores deficiência visual é aquele composto por cegos (total ausência de acuidade visual, que tem como maior de suas causas a catarata), somados ao grupo de pessoas com baixa visão.

Segundo o Censo de 2010 [IBGE, 2012], entre as pessoas que se declaram com alguma deficiência aponta que 837.076 possuem o ensino médio completo e o superior incompleto, e 338.128 concluem o ensino superior no Rio de Janeiro.

O levantamento de dados do mesmo Censo, $16^{\circ}$ Ergodesign - Congresso Internacional de Ergonomia e Usabilidade de Interfaces Humano Tecnológica: Produto, Informações Ambientes Construídos e Transporte

$16^{\circ}$ USIHC - Congresso Internacional de Ergonomia e Usabilidade de Interfaces Humano Computador

CINAHPA | 2017 - Congresso Internacional de Ambientes Hipermídia para Aprendizagem.

também para o Estado do Rio de Janeiro, informa que 3.069.661 pessoas se declaram com deficiência visual, das quais 483.414 enxergam com grande dificuldade (baixa visão) e 53.178 não enxergam de modo algum (cegas). Ainda nestes dois grupos, 29.242 pessoas com baixa visão e 5.771 pessoas cegas se encontram na faixa etária de 15 a 24 anos de idade, quando se dá o processo de preparação e transição do ensino médio para o ensino superior.

O Censo do Ensino Superior [INEP, 2014] aponta que em 2013 eram quase 30.000 alunos com deficiências diversas inscritos em cursos universitários, em sua maioria presenciais. Este número representa para as instituições de ensino superior a necessidade de cumprir o disposto nas leis de acessibilidade, visando incluir, entre todos os candidatos com deficiência, os candidatos e alunos com deficiência visual.

\subsection{Da Declaração Universal dos Direitos Humanos à lei de inclusão por cotas - $O$ direito à educação}

Embora em 1948, à ocasião de sua publicação, a Declaração Universal dos Direitos Humanos [ONU, 1948] já previsse o acesso à educação como direito fundamental a todos, foi necessário mais tempo para que as necessidades especiais e individuais emergissem, quebrando os paradigmas iniciais previstos pelos Direitos Humanos para os ambientes escolares e universitários, que não previam detalhamento nem diferenciação de tratamento.

Para detalhar e especificar a Educação como um direito das pessoas com deficiência, foi realizada Conferência Mundial Sobre Necessidades Educacionais Especiais [UNESCO,1994], que deu origem a Declaração de Salamanca, o segundo documento importante, que dará subsídios as leis brasileiras a que se refere este artigo.

A Declaração de Salamanca atravessou décadas como um dos principais compromissos das nações participantes - entre elas o Brasil; em reestruturar suas leis a fins de viabilizar a educação acessível a todos.

A mudança se deu de forma lenta e gradativa, quando a promoção da acessibilidade realizada
Realização:

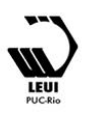




\section{$16^{\circ}$}

\section{ERGODESIGN USIHC CINAHPA}

pela ONU ao redor do mundo por fim alcançou as leis brasileiras relacionadas, [BRASIL, 2000]. Esta lei trazia em seu texto, entre outros assuntos relevantes, a classificação para o termo 'barreiras', para assegurar a produção de seus efeitos.

Para a pessoa com deficiência visual, somente à ocasião decreto $n^{\circ} 5.296$ [BRASIL, 2004] que regulamentava a lei de promoção da acessibilidade, os seus direitos puderam ser discretamente percebidos. Este decreto trazia as primeiras definições e classificações para a deficiência visual, e só a partir de então qualquer reclamação por direitos poderia ser fundamentada, mesmo que em teoria. Entre estes direitos, a educação.

\section{MPF apura falta de acessibilidade em provas do Enem em 12 estados}

Para Procurador da República, MEC precisa prevenir este tipo de situação. Ministério diz que atendimentos especificos cresceram $226 \%$ em cinco anos.

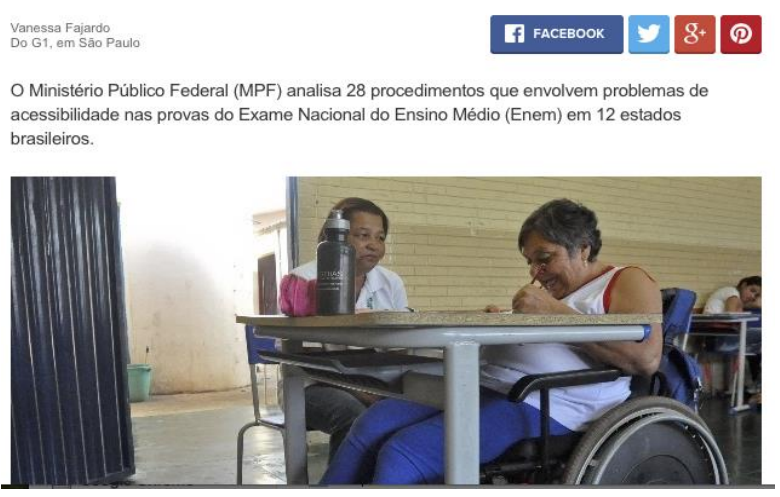

Notícia sobre acessibilidade à prova do Exame Nacional do Ensino Médio. Fonte: G1em 8. Mai. 2016

Implementado o primeiro Estatuto brasileiro da pessoa com deficiência [BRASIL, 2015], muito nas instituições de ensino superior deveria ser movimentado para realizar a acessibilidade de maneira condizente a um país-sede dos jogos olímpicos e paralímpicos. Esta lei já trazia em seu texto os princípios do Design Universal, novas especificações acerca da deficiência visual, e revisou a classificação vigente para o termo 'barreiras',

Passados os jogos, observou-se no segmento da educação a modificação da lei de inclusão, o que poderia vir a favorecer a acessibilidade. As pessoas com deficiência passam a ser incluídas no programa de cotas de instituições federais de $16^{\circ}$ Ergodesign - Congresso Internacional de Ergonomia e Usabilidade de Interfaces Humano Tecnológica: Produto, Informações Ambientes Construídos e Transporte

$16^{\circ}$ USIHC - Congresso Internacional de Ergonomia e Usabilidade de Interfaces Humano Computador

CINAHPA | 2017 - Congresso Internacional de Ambientes Hipermídia para Aprendizagem.

educação superior, que já contemplava estudantes vindos de escolas públicas, de baixa renda, negros, pardos e indígenas [BRASIL, 2016]

\subsection{Campos de atuação: Onde as leis e o design se encontram}

Para os efeitos deste artigo, será considerada a definição de barreiras presente no Estatuto da Pessoa com Deficiência [BRASIL, 2015]:

"IV - Qualquer entrave, obstáculo, atitude ou comportamento que limite ou impeça a participação social da pessoa, bem como o gozo, a fruição e o exercício de seus direitos à acessibilidade, à liberdade de movimento e de expressão, à comunicação, ao acesso à informação, à compreensão, à circulação com segurança, entre outros, classificadas em:

- Barreiras urbanísticas: as existentes nas vias e nos espaços públicos e privados abertos ao público ou de uso coletivo;

- Barreiras arquitetônicas: as existentes nos edifícios públicos e privados;

- Barreiras nos transportes: as existentes nos sistemas e meios de transportes;

- Barreiras nas comunicações e na informação: qualquer entrave, obstáculo, atitude ou comportamento que dificulte ou impossibilite a expressão ou o recebimento de mensagens e de informações por intermédio de sistemas de comunicação e de tecnologia da informação;

- Barreiras atitudinais: atitudes ou comportamentos que impeçam ou prejudiquem a participação social da pessoa com deficiência em igualdade de condições e oportunidades com as demais pessoas;

- Barreiras tecnológicas: as que dificultam ou impedem o acesso da pessoa com deficiência às tecnologias".

Com o intuito de entender como as barreiras acima expostas se relacionam com o campo da acessibilidade, foi considerada a definição de acessibilidade dada por Sassaki [2009] classificada 


\section{$16^{\circ}$}

ERGODESIGN

USIHC CINAHPA

em seis dimensões, quanto ao tipo de barreira enfrentada:

- Acessibilidade Arquitetônica - aquela que se relaciona à eliminação de barreiras físicas;

- Acessibilidade Comunicacional - relacionada à eliminação de barreiras na comunicação entre pessoas;

- Acessibilidade Metodológica - para a eliminação de barreiras nos métodos e técnicas do lazer, trabalho, educação, entre outros;

- Acessibilidade Instrumental - para eliminação de barreiras em instrumentos, ferramentas e utensílios;

- Acessibilidade Programática - para a eliminação de barreiras embutidas em políticas públicas, legislações, normas e regulamentações;

- Acessibilidade Atitudinal - para a eliminação de preconceitos, estereótipos, estigmas e discriminações no comportamento da sociedade para pessoas com deficiência.

O entendimento acerca da relação entre as dimensões de acessibilidade propostas pelo autor, quando relacionadas às definições apresentadas para barreiras de acessibilidade, representa uma ferramenta importante para a determinação do campo de ação onde os métodos, técnicas e abordagens levantadas na pesquisa teórica irão contribuir para tornar a acessibilidade em questão viável ao candidato com deficiência visual.

\section{0 processo e suas barreiras de acesso:}

\subsection{Formas de ingresso}

Para o candidato com deficiência visual, o desafio se torna ainda maior antes mesmo do processo seletivo. As inscrições, feitas em sua grande maioria por meios digitais, são um grande desafio à autonomia. Vencida esta etapa inicial, o candidato realiza as provas processos seletivos que por si já representam um grande desafio quando observamos a relação entre candidatos e vagas nas universidades do Rio de Janeiro, independente das vagas que lhes são asseguradas por lei. $16^{\circ}$ Ergodesign - Congresso Internacional de Ergonomia e Usabilidade de Interfaces Humano Tecnológica: Produto, Informações Ambientes Construídos e Transporte

$16^{\circ}$ USIHC - Congresso Internacional de Ergonomia e Usabilidade de Interfaces Humano Computador

CINAHPA | 2017 - Congresso Internacional de Ambientes Hipermídia para Aprendizagem.

Para as principais universidades do país, o Exame Nacional do Ensino Médio - ENEM é utilizado como principal critério de seleção, podendo complementar ou até mesmo substituir os vestibulares próprios. [MEC, 2016] O Enem é composto por quatro provas objetivas, com 45 questões de múltipla escolha cada, e uma redação. A realização das provas é dividida em dois dias.

Por meio do Sistema de Seleção Unificada - SISU [MEC, 2017], as instituições públicas de ensino superior oferecem vagas aos participantes do ENEM. A nota do Enem é adotada como fase única de seleção por 131 universidades federais e estaduais pelo país.

Ainda que oferecendo vagas pelo SISU, algumas instituições permanecem realizando seus próprios vestibulares.

De acordo com o Censo promovido pelo Guia do Estudante [ELDER; TOLEDO, 2016], das 2.056 instituições presentes no país, 1.993 têm vestibular próprio, e em 622 delas esse processo seletivo é a única forma de ingresso. Das públicas, boa parte delas são universidades estaduais.

Também são adotados os testes de habilidade específica (THE) como critério de seleção para cursos que exigem.

\subsection{Métodos, técnicas e abordagens}

Sob o esclarecimento acerca de como é realizado o processo seletivo nas universidades brasileiras, foi necessário entender em profundidade a realidade de pessoas com deficiência visual que o vivenciaram.

Para mapear esta experiência, foi realizado levantamento das informações de acessibilidade para candidatos com deficiência visual dispostos nos sites das Instituições de Ensino Superior mais relevantes no Rio de Janeiro. Dentre elas estão as 8 instituições filiadas ao Ministério da Educação e mais 4 outras instituições relevantes. Foram considerados nesta etapa:

- A disponibilidade de informações de acessibilidade do site conforme disposto na lei de acesso à informação [BRASIL,2011]; 


\section{$16^{\circ}$}

\section{ERGODESIGN USIHC CINAHPA}

- Quantas páginas/redirecionamentos são necessárias para alcançar as informações sobre o meio de ingresso;

- Quantas páginas/redirecionamentos são necessárias para alcançar a sessão de inscrições;

- Se a universidade informa seu núcleo de acessibilidade, conforme o Programa de Acessibilidade à educação superior, disposto no decreto $n^{\circ}$ 5.296/2004 [BRASIL, 2004]

O levantamento de informações foi realizado a partir da navegação pelo site das seguintes instituições de ensino superior: CEFET, PUC-Rio, UCP, UFRJ, UFRRJ, UNI Rio, UERJ, UFF, UVA, UCAM, UNESA, Uni SUAM.

Também foram realizadas entrevistas semiestruturadas com 12 voluntários até o momento. Dos voluntários entrevistados, 9 são cegos e 3 com baixa visão. A estrutura da entrevista estava dividida em 5 blocos:

- Levantamento de informações pessoais relevantes;

- Levantamento de informações acerca da inclusão e acessibilidade vivenciadas no ensino básico;

- Levantamento de informações sobre acessibilidade processos seletivos realizados;

- Levantamento de informações sobre a acessibilidade na estrutura do curso escolhido

- Levantamento de informações sobre o suporte dado pela universidade para as barreiras encontradas

De acordo com BARDIN [2016], a análise de conteúdo é um conjunto de técnicas de análise aplicadas à comunicação para descrever de maneira sistemática e objetiva o conteúdo de mensagens. Estas mensagens, que podem ser apresentadas de forma escrita, oral, icônica, sonora entre outras formas; são o veículo principal para a obtenção de indicadores quantitativos ou não quantitativos, para a realização de inferências deste conteúdo. $16^{\circ}$ Ergodesign - Congresso Internacional de Ergonomia e Usabilidade de Interfaces Humano Tecnológica: Produto, Informações Ambientes Construídos e Transporte

$16^{\circ}$ USIHC - Congresso Internacional de Ergonomia e Usabilidade de Interfaces Humano Computador

CINAHPA | 2017 - Congresso Internacional de Ambientes Hipermídia para Aprendizagem.

A análise de conteúdo, conforme a autora, é dividida em 3 etapas: 1) A pré análise: organização da análise propriamente dita: a seleção dos documentos, a formulação das hipóteses e/ou objetivos e a elaboração dos indicadores (as unidades a serem codificadas); 2) A exploração do material: Aplicação sistemática dos indicadores elaborados, o estabelecimento de regras de enumeração (contagem) e a categorização; e 3 ) $\mathrm{O}$ tratamento dos resultados e interpretação: É a apresentação dos resultados e a análise (inferências e interpretação) do material.

Com o intuito de organizar as informações extraídas do conteúdo das entrevistas, para embasamento teórico, foram encontrados alguns modelos para a compreensão de como se dá a relação humano-máquina e humano-sistema.

Segundo Moraes e Mont'Alvão, [2010], Modelagem Comunicacional do Sistema lida com a transmissão da informação entre os subsistemas humanos e da máquina. Os subsistemas humanos podem ser classificados como: A) De tomada de informação/ percepção: que compreende os sentidos humanos (Tato, visão, paladar, olfato e audição); B) de resposta/ regulação: que compreende as ações realizadas (Palavras, gestos, deslocamentos e posturas).

Os subsistemas da máquina podem ser: A) os que fornecem informações para serem processadas pelo homem; B) os que recebem as ações do homem.

Garcia [2012] define comunicação como um processo pelo qual a informação pode ser emitida, recebida ou trocada, por meio de linguagem falada, gesticulada, escrita ou de símbolos, entre duas ou mais pessoas, de forma direta ou indireta.

Para a autora, o acesso a informação se dá de forma completa quando a livre movimentação física (mobilidade) está garantida, seja no deslocamento do indivíduo até a fonte da informação, ou a entrega da fonte da informação para o indivíduo; assim como o livre processo de comunicação - a transmissão da informação do emissor até o receptor; e a garantia da compreensão - quando o indivíduo entende o significado daquilo que o emissor da informação quis transmitir. Desta forma, Modelagem
Realização:

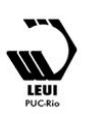




\section{$16^{\circ}$}

\section{ERGODESIGN USIHC CINAHPA}

Comunicacional do Sistema será responsável por guiar análise dos aspectos informacionais extraídos dos sites das universidades.

De forma gradual, o acesso a informação por meios digitais revelou barreiras comunicacionais e tecnológicas, que podem ser identificadas em duas direções: Na direção do conteúdo para a pessoa quando o acesso à informação se encontra ineficiente - seja pelo sistema, pelo meio de acesso ou pelo conteúdo; e na direção da pessoa para o conteúdo - quando compreensão e os fatores cognitivos da pessoa se apresentam deficientes. Isto revela um espaço entre a comunicação e a compreensão humana, que precisou ser desvendado.

Da mesma maneira que o acesso à informação revela barreiras comunicacionais e tecnológicas, a experiência de realização dos processos seletivos revela barreiras arquitetônicas, urbanísticas de transportes e até mesmo atitudinais, de acordo com o processo individual do candidato com deficiência visual.

É possível considerar também, neste aspecto, que intervenções são feitas pelos mesmos para viabilizar a acessibilidade relacionada, como processo adaptação pessoal de cada um.

Com o olhar voltado à esta experiência pessoal da pessoa com deficiência, os sete princípios do Design Universal, presentes no Estatuto da Pessoa com Deficiência, foram criados no intuito de conduzir o processo de desenvolvimento de produtos e ambientes acessíveis a todos, na maior extensão possível, sem à necessidade de adaptação [TCUD, 2008]. São eles:

- Uso Equitativo: O projeto precisa ser útil e comercializável às pessoas com diferentes habilidades.

- Uso Flexível: O projeto deve alcançar o máximo de preferências e habilidades individuais

- Uso simples e intuitivo: O projeto deve ser de fácil entendimento, independente da experiência que o usuário traz, seu conhecimento, habilidades idiomáticas ou nível de concentração. $16^{\circ}$ Ergodesign - Congresso Internacional de Ergonomia e Usabilidade de Interfaces Humano Tecnológica: Produto, Informações Ambientes Construídos e Transporte

$16^{\circ}$ USIHC - Congresso Internacional de Ergonomia e Usabilidade de Interfaces Humano Computador

CINAHPA | 2017 - Congresso Internacional de Ambientes Hipermídia para Aprendizagem.

- Que tenha a informação de fácil percepção: O projeto deve comunicar efetivamente as informações necessárias ao usuário, independente das suas habilidades sensoriais ou das condições do ambiente.

- Tolerância ao erro: O projeto deve minimizar o perigo e consequências adversas de ações acidentais ou sem intenção.

- Demande baixo esforço físico: O projeto deve ter a utilização eficiente, confortável e com o mínimo de fadiga.

- Dimensão e espaço favoráveis para a aproximação e uso: Não importando o tamanho do corpo, postura e mobilidade do usuário.

Estas diretrizes, muito presentes no desenvolvimento de projetos de produtos e ambientes acessíveis em todo o mundo, guiarão a análise das lacunas de acessibilidade arquitetônica e instrumental surgidas no conteúdo das entrevistas realizadas.

Para as lacunas de acessibilidade comunicacional, metodológica e atitudinal reveladas pelo conteúdo das entrevistas, serão utilizados os três princípios do Design Universal para a Aprendizagem, apresentados pelo National Center on Universal Design for Learning [2011] como guias. São eles:

- Fornecer múltiplos meios de representação: utilizar diferentes recursos no intuito de passar a informação da maneira mais compreensível possível por parte do aluno;

- Fornecer múltiplos meios para a ação e expressão: para administrar estratégias, ferramentas e tecnologias a favor da compreensão

\section{- Fornecer múltiplos meios para o} engajamento: para promover a motivação e o interesse por parte dos alunos

Com base nas definições apresentadas pelos autores e pelos métodos, foi possível formatar modelos que serviram de guias para a fase de pré análise do conteúdo. São eles: 


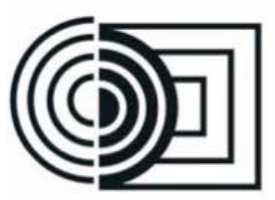
CINAHPA

\begin{tabular}{|c|c|}
\hline \multicolumn{2}{|c|}{ Modelagem Comunicacional do Sistema } \\
\hline Acessibilidade comunicacional & $\begin{array}{c}\text { Barreiras na comunicação e } \\
\text { informação }\end{array}$ \\
\hline Acessibilidade instrumental & Barreiras tecnológicas \\
\hline
\end{tabular}

Tabela 1. Estrutura de análise para as questões de acessibilidade presentes no âmbito comunicacional

\begin{tabular}{|l|c|}
\hline \multicolumn{2}{|c|}{ Princípios do Design Universal } \\
\hline Acessibilidade arquitetônica & $\begin{array}{c}\text { Barreiras urbanísticas } \\
\text { Barreiras arquitetônicas }\end{array}$ \\
\hline Acessibilidade instrumental & Barreiras nos transportes \\
\hline
\end{tabular}

Tabela 2. Estrutura de análise para as questões de acessibilidade presentes no âmbito físico

\begin{tabular}{|c|c|}
\hline \multicolumn{2}{|c|}{ Princípios do Design Universal para a Aprendizagem } \\
\hline Acessibilidade comunicacional & $\begin{array}{c}\text { Barreiras nas comunicações e na } \\
\text { informação }\end{array}$ \\
\hline Acessibilidade metodológica & $\begin{array}{c}\text { Barreiras nas comunicações e na } \\
\text { informação }\end{array}$ \\
\hline Acessibilidade atitudinal & Barreiras atitudinais \\
\hline
\end{tabular}

Tabela 3. Estrutura de análise para as questões de acessibilidade presentes no âmbito cognitivo de aprendizagem

\section{eflexões e próximos passos}

Até o momento da escrita deste artigo, a etapa de levantamento de informações realizada pelas entrevistas semiestruturadas se encontrava em andamento, o que não viabiliza conclusões, mas a apresentação parcial dos dados e algumas reflexões, a partir da exploração do conteúdo das entrevistas na etapa de pré análise.

O conteúdo foi inicialmente segmentado e extraído das falas dos entrevistados, para em próxima etapa serem transformados formalmente em unidades de registro. Em seguida, estas unidades de registro serão agrupadas em unidades de contexto, com o objetivo de realizar a análise e o tratamento destas informações. Esta análise será realizada à luz da estrutura teórica apresentada nos quadros do subitem anterior deste artigo, que incorporam o objetivo da pesquisa.

Dentro desta organização, foram extraídas algumas informações relevantes que revelam barreiras de acessibilidade que em teoria não deveriam existir, de acordo com o texto das leis brasileiras relacionadas. Estão entre elas:

- Entre os entrevistados, a maior parte declara ter estudado em escolas públicas e particulares de $16^{\circ}$ Ergodesign - Congresso Internacional de Ergonomia e Usabilidade de Interfaces Humano Tecnológica: Produto, Informações Ambientes Construídos e Transporte

$16^{\circ}$ USIHC - Congresso Internacional de Ergonomia e Usabilidade de Interfaces Humano Computador

CINAHPA | 2017 - Congresso Internacional de Ambientes Hipermídia para Aprendizagem.

ensino regular, embora tivessem por algum momento passado por institutos especializados para adaptação e aprendizado da escrita em leitura em Braille. Estudar em escolas regulares não significa a garanta aprendizado pleno por parte do aluno, que muitas vezes chega para fazer as provas sem ter o conhecimento do conteúdo.

- Existe uma preferência por fazer a prova do Exame Nacional do Ensino Médio - ENEM, pois somente por ele é possível obter bolsas de estudo pelo Programa Universidade Para Todos -

PROUNI. Em paralelo a este fator, também fazem a prova dos vestibulares próprios das Instituições de Ensino Superior como outra opção.

- Para a realização das provas, os candidatos fazem a solicitação de auxílio de Perkins, reglete, ledores e transcritores; além do tempo adicional que nem sempre é suficiente quando a prova em questão é entregue em braile.

- Alguns entrevistados relatam ter vivenciado a oportunidade rara de terem feito a prova em computador, que representa o desejo de quase a totalidade deles. Este desejo é expressado por conta do despreparo dos ledores que transmitem o conteúdo das provas, e dos transcritores que transcrevem o conteúdo ditado pelo candidato. A grande maioria dos entrevistados revela ter se sentido prejudicado nas avaliações por conta de ações equivocadas dos ledores e transcritores.

- Quanto às questões de ambiente construído, poucas universidades apesentam trilhas táteis e informações que de alguma maneira alcance o aluno com deficiência visual e que lhes ofereça autonomia para ir e vir dentro das mesmas. Geralmente estas trilhas táteis estão presentes apenas na entrada da instituição.

- Os ambientes de educação à distância não apresentam conteúdos acessíveis aos leitores de tela. Grande parte dos entrevistados relatam que esta poderia ser uma ferramenta poderosa no combate às barreiras comunicacionais apresentadas nas salas de aula, mas na prática tornou-se apenas mais uma entre as outras tantas já encontradas.

Além do conteúdo das entrevistas, é possível perceber a omissão no texto das leis brasileiras, de 
$16^{\circ}$ USIHC - Congresso Internacional de Ergonomia e Usabilidade de Interfaces Humano Computador

CINAHPA | 2017 - Congresso Internacional de Ambientes Hipermídia para Aprendizagem.

classificação de barreiras para a dimensão programática da acessibilidade; o que revela a fragilidade e a falta de estrutura das políticas públicas, que são essenciais ao suporte das leis e a prática de seus efeitos.

Para o Design, esta falta de estrutura pode tanto representar uma oportunidade de desenvolvimento para seus métodos e abordagens, como um abismo para a sua prática. Por um lado, a pesquisa em design ganha mais um campo de investigação; e por outro, a prática projetual perde pela insegurança que envolve os requisitos de sua prática.

Para viabilizar a acessibilidade, é necessária a profundidade na investigação, e a análise particular de cada caso, pois as leis não são suficientes para a eliminação de barreiras no contexto do ensino superior brasileiro. Elas estão presentes em todas as dimensões da acessibilidade apresentadas.

\section{BIBLIOGRAFIA}

BARDIN, L. Análise de Conteúdo. São Paulo: Edições 70, 2016. 280p, Pág. 44.

BRASIL, Ministério da educação, ENEM apresentação, portal MEC 2016. Disponível em: http://portal.mec.gov.br/enem-sp-2094708791 acesso em 22 fev. 2017

BRASIL, Ministério da educação, Sistema de Seleção Unificada SISU, o que é o SiSU, portal MEC 2017. Disponível em: http://sisu.mec.gov.br/ acesso em 22 fev. 2017

BRASIL, Casa Civil, Subchefia para assuntos jurídicos, Decreto no 5.296 de 2 de dezembro de 2004 de promoção da acessibilidade, disponível em:http://www.planalto.gov.br/ccivil 03/ ato20042006/2004/decreto/d5296.htm Acesso em: em 26 out. 2016

BRASIL, Casa Civil, Subchefia para assuntos jurídicos, Lei $n^{\circ} 10.098$ de 19 de dezembro de 2000 de promoção da acessibilidade, disponível em:http://www.planalto.gov.br/ccivil_03/Leis/L10 098.htm Acesso em: 26 out. 2016

BRASIL, Casa Civil, Subchefia para assuntos jurídicos, Lei $\mathbf{n}^{\circ} \mathbf{1 2 . 5 2 7}$ de 18 de novembro de 2011 de acesso à informação, disponível em: http://www.planalto.gov.br/ccivil 03/ ato20112014/2011/lei/112527.htm Acesso em: em 6 fev. 2017

BRASIL, Casa Civil, Subchefia para assuntos jurídicos, Lei $\mathbf{n}^{\circ} \mathbf{1 3 . 1 4 6}$ de 6 de julho de 2015, Estatuto da pessoa com deficiência, disponível em:http://www.planalto.gov.br/ccivil 03/ ato20152018/2015/Lei/L13146.htm Acesso em: 26 out. 2016

BRASIL, Casa Civil, Subchefia para assuntos jurídicos, Lei $\mathbf{n}^{\circ} \mathbf{1 3 . 4 0 9}$ de 28 de dezembro de 2016, disponível em:

http://www.planalto.gov.br/ccivil_03/_ato20152018/2016/lei/L13409.htm Acesso em: 6 fev. 2017

National Center on Universal Design for Learning, UDL guidelines version 2.0, 2011, Disponível em: http://www.udlcenter.org/aboutudl/udlguidelines/d ownloads, acesso em 11.dez. 2016.

\section{GARCIA, Carla Cristina, Sociologia da}

Acessibilidade, IESDE - Brasil, 2012, pág. 69

ELDER, Guilherme; TOLEDO, Simone; De quantas maneiras dá para entrar na universidade, artigo guia do estudante, 25 nov. 2016, disponível em:

http://guiadoestudante.abril.com.br/universidades/d e-quantas-maneiras-da-para-entrar-nauniversidade/ acesso em 22 fev. 2017

\section{IBGE, CENSO Demográfico 2010 -}

Características gerais da população, religião e pessoas com deficiência, Instituto Brasileiro de Geografia e Estatística 2012 disponível em: http://biblioteca.ibge.gov.br/visualizacao/periodico s/94/cd_2010_religiao_deficiencia.pdf Acesso em: 1 jun. 2016

INEP, Instituto Nacional de Estudos e Pesquisas Educacionais Anísio Teixeira, Censo da Educação Superior, 09, set. 2014, disponível em:

http://portal.inep.gov.br/visualizar/-

lasset publisher/6AhJ/content/matriculas-noensino-superior-crescem-3-8 visualizado em 01 , jun. 2016

Moraes, Anamaria de; Mont'Alvão, Cláudia, Ergonomia, Conceitos e Aplicações, Rio de Janeiro, 2AB, 2009, 4.a edição ampliada, pág. 121

Organização das Nações Unidas, Declaração Universal dos Direitos Humanos, 10 dez. 1948,
Realização:

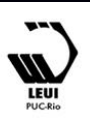




\section{$16^{\circ}$}

ERGODESIGN USIHC CINAHPA $16^{\circ}$ Ergodesign - Congresso Internacional de Ergonomia e Usabilidade de Interfaces Humano Tecnológica: Produto, Informações Ambientes Construídos e Transporte

$16^{\circ}$ USIHC - Congresso Internacional de Ergonomia e Usabilidade de Interfaces Humano Computador

CINAHPA | 2017 - Congresso Internacional de Ambientes Hipermídia para Aprendizagem.

disponível em:

http://www.onu.org.br/img/2014/09/DUDH.pdf

Acesso em 23.10.2016

SASSAKI, Romeu Kazumi. Inclusão: acessibilidade no lazer, trabalho e educação, Revista Nacional de Reabilitação - Reação, São Paulo, Ano XII, mar/abr. 2009, p. 10-16.

The Center for Universal Design, Universal Design History, Barrier-Free to Universal Design, North Carolina State University, College of Design, 2008, disponível em:

https://www.ncsu.edu/ncsu/design/cud/about ud/u dhistory.htm acesso em: 26 out. 2016

UNESCO, Conferência mundial sobre necessidades educacionais especiais, Declaração de Salamanca e Enquadramento da Ação nas Áreas de Necessidades Educativas Especiais, Salamanca, Espanha 7-10 jun. 1994 Disponível em:http://portal.mec.gov.br/seesp/arquivos/pdf/sala manca.pdf

World Health Organization, Statistics for Visually Impairment: disponível em: http://www.who.int/mediacentre/factsheets/fs282/e n/\# - Fact Sheet N ${ }^{\circ} 282$, Acesso em 29 Abr. 2016

\section{Agradecimentos}

A pesquisa na qual este artigo se fundamenta não teria sido realizada sem o apoio e parceria dos voluntários entrevistados; do Laboratório de Ergodesign e Usabilidade de Interfaces da Pontifícia Universidade Católica do Rio de Janeiro - LEUI PUC-Rio; e do Conselho Nacional de Pesquisa e Desenvolvimento do Governo federal $\mathrm{CNPq}$ 